\title{
Familial occipital neuralgia with sporadic NIN: a reply
}

\author{
Yu Wang • Chuan-Yong Yu • Lin Huang • \\ Franz Riederer • Dominik Ettlin
}

Received: 19 August 2011/Accepted: 22 August 2011/Published online: 4 September 2011

(C) The Author(s) 2011. This article is published with open access at Springerlink.com

\section{Dear Sir,}

We thank Dr. Alex Alfieri and Dr. Christian Strauss for their interest and comments on our article [1]. They raise the appropriate question if the familial clustering of occipital neuralgia $(\mathrm{ON})$ and intermedius nerves neuralgia (NIN) might be coincidental rather than due to a common pathophysiological correlate.

We agree that the occipital nerve and the nervus intermedius have different morphological, anatomical, embryological and functional characteristics. We do not understand, however, why these differences were to exclude a common pathophysiology, namely regarding potential dysfunction of Nav1.7 sodium-channels? The few Swiss and Chinese family cases reported [1, 2] have insufficient statistical power to draw a final conclusion in either way, i.e. sporadic NIN or NIN linked to ON. We speculate that NIN, in our report, is not a sporadic familial occurrence based on the following observations: (1) NIN is an extremely uncommon neuralgia and the co-existence in two members of one family is, therefore, unlikely to be a sporadic event. It might exist subclinically in the other family members as well; (2) familial clustering of neuralgia or neuropathy of many other (morphologically diverse) peripheral nerves has been observed in a nationwide database of Sweden [3]; (3) though Alfieri and Strauss

Y. Wang $(\bowtie) \cdot$ C.-Y. Yu $\cdot$ L. Huang

Department of Neurology, Epilepsy and Headache Group,

The First Hospital of Anhui Medical University,

Jixi Road 218, Hefei 230022, China

e-mail: yw4d@hotmail.com

F. Riederer · D. Ettlin

Department of Neurology, University Hospital Zurich,

Plattenstrasse 11, 8032 Zurich, Switzerland themselves in an interesting paper reported on the long history of anatomical descriptions of the nervus intermedius, the anatomy of this small nerve is not yet fully elucidated [4]. The current common definition of this nerve as a purely sensory and parasympathetic branch of the seventh cranial nerve may not cover all aspects.

Thus, the answer to the question raised by Alfieri and Strauss will likely be approached by publication of additional clinical reports on a familial co-occurrence of cranial neuralgias, as well as by more detailed basic science and genetic investigations.

Conflict of interest None.

Open Access This article is distributed under the terms of the Creative Commons Attribution License which permits any use, distribution and reproduction in any medium, provided the original author(s) and source are credited.

\section{References}

1. Wang Y, Yu CY, Huang L, Riederer F, Ettlin D (2011) Familial neuralgia of occipital and intermedius nerves in a Chinese family. J Headache Pain 12(4):497-500

2. Riederer F, Sandor PS, Linnebank M, Ettlin DA (2010) Familial occipital and nervus intermedius neuralgia in a Swiss family. J Headache Pain 11(4):335-338

3. Hemminki K, Li X, Sundquist K (2007) Familial risks for nerve, nerve root and plexus disorders in siblings based on hospitalisations in Sweden. J Epidemiol Community Health 61(1):80-84

4. Alfieri A, Strauss C, Prell J, Peschke E (2010) History of the nervus intermedius of Wrisberg. Ann Anat 192(3):139-144 